\title{
Main cardiac surgery procedures performed in Poland in 2012 (according to the National Registry of Cardiac Surgery Procedures - KROK, Warsaw, Poland 2013)
}

\author{
Bohdan Maruszewski \\ Professor of Cardiothoracic Surgery \\ Chief Surgeon \\ Director of the Department of Pediatric Cardiothoracic Surgery Children's Memorial Health Institute, Warsaw, Poland \\ President of the Polish Cardiac Surgeons Club
}

Kardiochirurgia i Torakochirurgia Polska 2013; 3: 300-304

The National Registry of Cardiac Surgery Procedures was established in 2005 following the decision of the Minister of Health, Prof. Zbigniew Religa. Since the very beginning this Registry has been mandatory for all departments of cardiothoracic surgery, including public and non-public units for adults and children.

Collecting the data on all cardiac procedures at the national level enables comparison of results between individual units and is aimed at the improvement of early and long-term outcomes. Evaluation of the quality of care requires preoperative risk stratification, which is achieved using Euroscore in adult patients and Aristotle Basic Score and EACTS/STS Mortality Score in children. The data of 39 CTS Units including 9 congenital departments are collected in a unified and dedicated system. The data set includes all fields of the EACTS adult database and EACTS Congenital Database. Additionally the data on manpower, infrastructure of cardiothoracic units and scientific activities are collected. The data on congenital procedures are automatically transferred to the EACTS Congenital Database. The analysis of outcomes is performed using the limit of two standard deviations for each unit in every procedure category. This methodology allows for defining the outliers - units where the mean mortality in a given group of procedures extends beyond 2 SD. Semi-annual and annual reports are created and distributed among the CTS health care providers, supervisors and payers. The long-term survival in patients after cardiac surgery is analyzed using the national death registry and Kaplan-Meier survival curves are drawn for main groups of procedures. That is made available for every participating unit. Until the end of 2012 the data on 175732 cardiac procedures including early outcomes and complications have been collected and analyzed.
The annual report in 2012 shows the data on 26914 cardiac procedures including 2657 congenital. During the last seven years (2006-2012) the volume of congenital heart surgical procedures increased by $17 \%$. Currently, the neonatal age group (564 operations) makes up $21.2 \%$ of all congenital procedures. $60 \%$ of all (1577) operations are performed in children (infants) under 1 year of age.

In Poland all types of congenital surgery are performed. Our demographic specificity is related to very low frequency of therapeutic abortion due to congenital heart defects. That is why $20 \%$ of all neonatal operations are performed in neonates with a functionally single ventricle. The Norwood operation in Poland (87 in 2012) is the second most frequent after PDA ligation in neonates. The early outcomes compare favorably with the best international results. The volumes vary substantially between congenital departments. Three biggest congenital centers (Warsaw, Lodz and Cracow) perform (1 206 - 45.4\%) almost half of all operations, while the three smallest units do less than 150 procedures per unit, per year. Also the spectrum and complexity of congenital operations differ importantly between departments.

In summary, congenital heart surgery in Poland as presented in the Annual Report 2012 is characterized by the predominance of palliative treatment in children with the most complex univentricular heart anatomy, a huge proportion of reoperations in patients requiring multi-stage surgical treatment, and substantial differences between congenital units in terms of volumes and complexity of patients. 


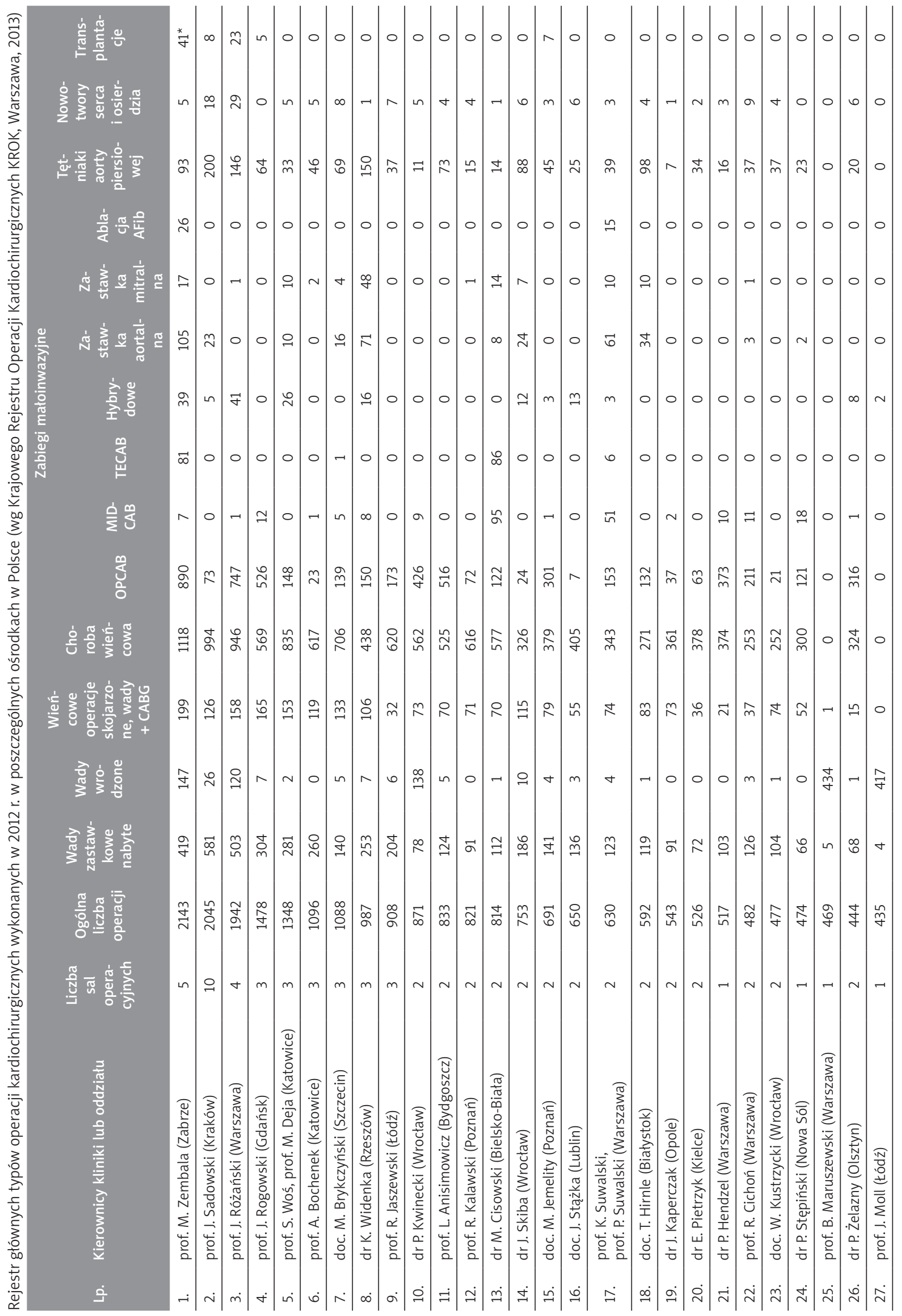




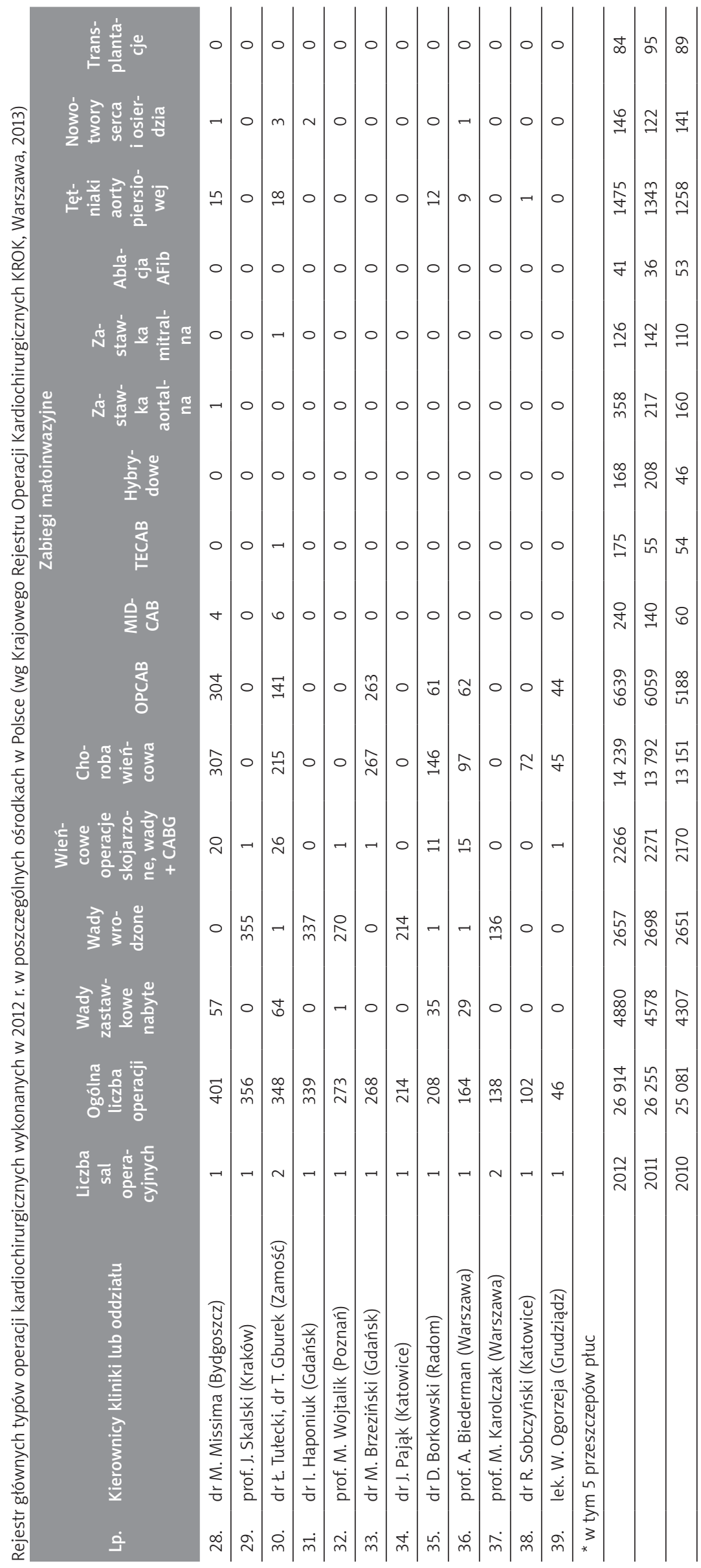




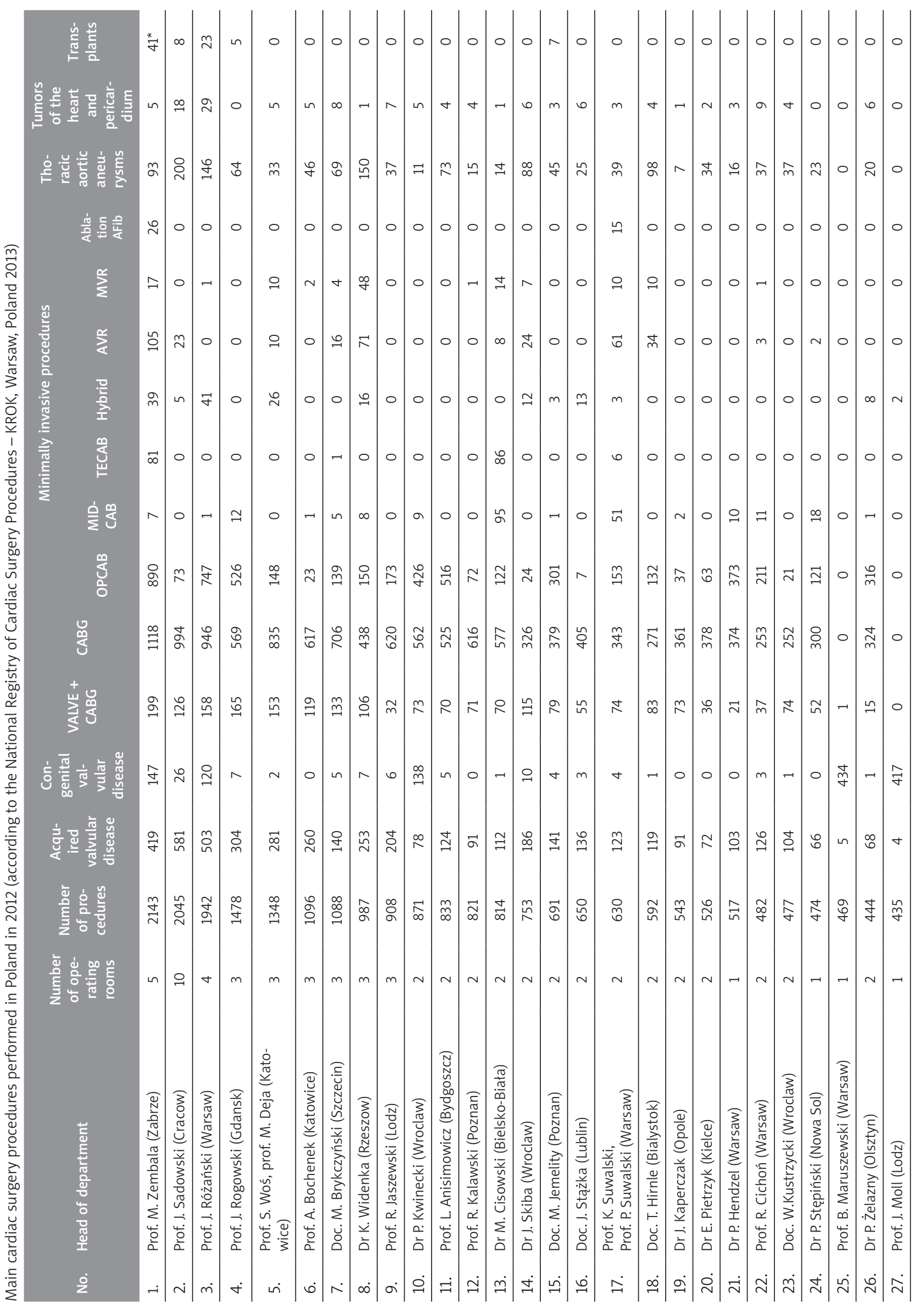




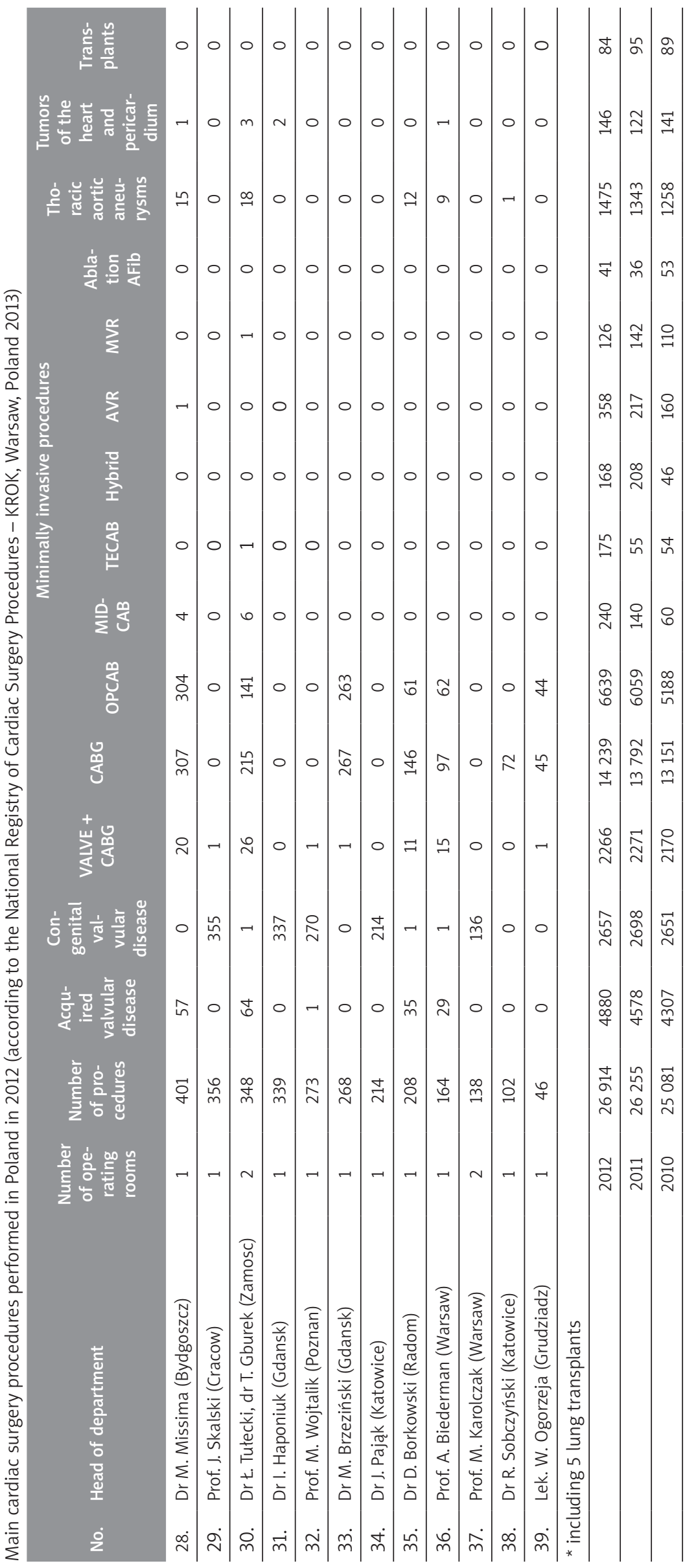

